\title{
The influence of chemical heterogeneities on the local mechanical behavior of a high- entropy alloy: a micropillar compression study
}

\author{
Anita Heczel $^{1 *}$, Megumi Kawasaki ${ }^{2}$, Dávid Ugi ${ }^{1}$, Jae-il Jang ${ }^{3}$, Terence G. Langdon ${ }^{4}$, Jenő \\ Gubicza $^{1}$ \\ ${ }^{1}$ Department of Materials Physics, Eötvös Loránd University, Budapest, Hungary \\ ${ }^{2}$ School of Mechanical, Industrial and Manufacturing Engineering, Oregon State \\ University, Corvallis, Oregon, USA \\ ${ }^{3}$ Division of Materials Science and Engineering, Hanyang University, Seoul, Republic of \\ Korea \\ ${ }^{4}$ Materials Research Group, Faculty of Engineering and the Environment, University of \\ Southampton, Southampton SO17 1BJ, U.K. \\ *Corresponding author: Tel: + 36-1-372-2845, Fax: +36-1-372-2811, \\ e-mail: heczel.anita@gmail.com
}

\begin{abstract}
The effect of the chemical inhomogeneities on the local mechanical behavior was studied in a $\mathrm{CoCrFeMnNi}$ high-entropy alloy. Micropillar compression revealed that, despite the difference in the chemical composition, the stress-strain behaviors in the two regions were almost identical. The size effect was negligible in the micropillar compression experiments.
\end{abstract}

Keywords: High-entropy alloy; Chemical heterogeneity; Micropillar compression; Flow stress

\section{Introduction}

High-entropy alloys (HEAs) are in the focus of materials science due to their outstanding properties, such as high strength [1]. HEAs are composed of four or more metallic elements with equal or nearly equal fractions [2]. HEAs have attractive properties for engineering applications such as high hardness, wear resistance, high-temperature softening resistance and oxidation resistance [2,3]. Bulk HEA materials are usually solidified from melts. During the nucleation process, the chemical compositions of the crystalline nuclei and the remaining molten material are different. These chemical heterogeneities may remain in the solidified 
HEAs even if the alloys are remelted in order to improve their homogeneity. Our recently published study on $\mathrm{Co}_{20} \mathrm{Cr}_{20} \mathrm{Fe}_{20} \mathrm{Mn}_{20} \mathrm{Ni}_{20}$ HEA revealed that the spatial distribution of the five chemical elements was inhomogeneous as the concentrations of the constituents were different in the dendrite arms and the interdendritic regions [4]. This Cantor alloy is the most commonly investigated HEA in the literature which has a simple fcc phase with a dendrite structure. For an understanding of the mechanical properties of HEAs, a study of the influence of chemical heterogeneities on the local mechanical behavior is crucial. At the same time, to the knowledge of the authors, this effect has not been investigated experimentally.

In this study, the local mechanical properties were investigated by micropillar compression tests in a nanocrystalline $\mathrm{Co}_{20} \mathrm{Cr}_{20} \mathrm{Fe}_{20} \mathrm{Mn}_{20} \mathrm{Ni}_{20}$ HEA. Micropillar compression is an excellent technique to characterize the plastic properties at small scales [5,6]. Liu et al. [6] used this technique for probing the mechanical behavior of the different crystalline phases in an $\mathrm{Al}_{0.8} \mathrm{CoCrCuFeNi} \mathrm{HEA}$. In our investigations, micropillars were fabricated in the regions with different chemical compositions by focused ion beam (FIB) milling. Then, the effect of the chemical composition on the compression behavior was tested using a nanoindenter equipped with a flat tip. The flow stress measured by micropillar compression was compared with the macroscopic flow stress determined by hardness testing.

\section{Material and methods}

$\mathrm{A} \mathrm{Co}_{20} \mathrm{Cr}_{20} \mathrm{Fe}_{20} \mathrm{Mn}_{20} \mathrm{Ni}_{20}$ (in at.\%) HEA material was processed by drop-casting into a mold. Then, a disk with a diameter of $\sim 10 \mathrm{~mm}$ and a thickness of $\sim 0.8 \mathrm{~mm}$ was cut from the as-cast sample. This disk was processed by HPT under quasi-constrained conditions for two turns at RT [4]. The rate of torsion and the pressure were $1 \mathrm{rpm}$ and $3.0 \mathrm{GPa}$, respectively. Our former study [4] showed that the grain size was refined to $\sim 27 \mathrm{~nm}$ at the periphery of this disk. The surface of the HPT-processed sample was mechanically polished by SiC abrasive papers and a colloidal silica suspension with a particle size of $40 \mathrm{~nm}$. The mechanically polished surface was further processed by electropolishing at $25 \mathrm{~V}$ and $1 \mathrm{~A}$ using an electrolyte with a composition of $70 \%$ ethanol, $20 \%$ glycerine and $10 \%$ perchloric acid (in vol.\%).

The spatial distributions of different elements were studied by energy-dispersive X-ray spectroscopy (EDS). The EDS experiments were carried out in an FEI Quanta 3D scanning electron microscope (SEM). The local mechanical behavior of the nanocrystalline HEA was studied by micropillar compression. Therefore, micropillars with square cross-sections were fabricated at the periphery of the HPT-processed HEA disk using a FIB technique in SEM. 
The edge and the height of the pillars were 1 and $2 \mu \mathrm{m}$, respectively. The compression experiments were carried out by a home-made indenter device using a flat-ended cylindrical punch. The precision of the indentation depth and the load were $\sim 10^{-5} \mu \mathrm{m}$ and $\sim 10^{-5} \mathrm{mN}$, respectively. In the present experiments the maximum applied load was $\sim 1.5 \mathrm{mN}$. To ensure reproducibility of the micro-compression data, at least three micropillars were fabricated and compressed in each characteristic region. SEM images were taken on the pillars before and after deformation.

\section{Results and discussion}

Fig. 1 shows EDS maps for the five constituents in the CoCrFeMnNi HEA. These maps reveal inhomogeneities in the concentrations of the five elements. The bright and dark regions in Fig. 1 indicate enrichment and depletion of the constituents, respectively. It can be seen that $\mathrm{Co} / \mathrm{Cr} / \mathrm{Fe}$ and $\mathrm{Mn} / \mathrm{Ni}$ elements behave in a complementary way. The dashed and solid white circles in Fig. 1 indicate $\mathrm{Co} / \mathrm{Cr} / \mathrm{Fe}$-rich and $\mathrm{Mn} / \mathrm{Ni}$-rich regions, respectively. The EDS maps were used to select regions where the micropillars were fabricated. The average chemical composition for the $\mathrm{Co} / \mathrm{Cr} / \mathrm{Fe}$-rich regions studied by pillar compression was $21.0 \%$ Co, $21.9 \% \mathrm{Cr}, 22.3 \% \mathrm{Fe}, 16.3 \% \mathrm{Mn}$ and $18.5 \% \mathrm{Ni}$. At the same time, for the Ni/Mn-rich regions the average chemical composition was $16.9 \% \mathrm{Co}, 17.4 \% \mathrm{Cr}, 16.3 \% \mathrm{Fe}, 25.3 \% \mathrm{Mn}$ and $24.1 \% \mathrm{Ni}$.

Micropillars were fabricated in the $\mathrm{Co} / \mathrm{Cr} / \mathrm{Fe}$-rich and $\mathrm{Mn} / \mathrm{Ni}$-rich regions using the FIB technique and then compressed using a flat-end diamond punch under a load-controlled condition. Fig. 2a shows a typical micropillar fabricated in a $\mathrm{Co} / \mathrm{Cr} / \mathrm{Fe}$ rich region before compression. Our former study [4] showed that the HPT-processed disk exhibited a texturefree microstructure with a very fine grain size $(\sim 27 \mathrm{~nm})$. The dimensions of the pillars were selected as 1-2 $\mu \mathrm{m}$ which is larger than the grain size in order to avoid any effect of the crystallographic orientation on the compression results. In addition, the pillar size could not be much higher than the size of the volume studied by EDS (about $1 \mu \mathrm{m}$ for the constituents of CoCrFeMnNi HEA). After compression, the height of the pillars was reduced from $\sim 2$ to $\sim 1.8 \mu \mathrm{m}$ which corresponds to a residual strain of about $10 \%$ (see Fig. 2b).

Fig. 3 shows typical engineering stress-strain curves obtained by compression of micropillars for the $\mathrm{Co} / \mathrm{Cr} / \mathrm{Fe}$-rich and the $\mathrm{Mn} / \mathrm{Ni}$-rich regions. The stress was calculated as the ratio of the applied load and the initial area of the top surface of the micropillars determined by SEM. The strain was obtained as the ratio of the indenter displacement and the initial height of the micropillars. The experiments revealed that a saturation of the flow stress 
was achieved at a total strain of $\sim 13 \%$. The micropillar compression tests show that the saturation flow stress for the Mn/Ni-rich regions (1594 $\pm 65 \mathrm{MPa})$ agrees with the value determined for the $\mathrm{Co} / \mathrm{Cr} / \mathrm{Fe}$-rich regions $(1475 \pm 71 \mathrm{MPa})$ within experimental error. Therefore, the chemical heterogeneities have only a marginal effect on the local flow stress of the HEA.

It has been shown for other materials that a decrease in the size of the pillars led to a change in strength (referred to as "size effect") [7]. This effect can be checked for the present study if the flow stress measured by pillar compression is compared with the macroscopic flow stress. The average of the saturation flow stress values determined by pillar compression for the different regions was $1535 \pm 68 \mathrm{MPa}$. This value was compared to the macroscopic flow stress determined as one third of the macrohardness determined by Vickers indentation. The Vickers hardness was measured using a load of $500 \mathrm{~g}$ which gave an indent size of 40 $\mu \mathrm{m}$. Considering the length scale of the chemical heterogeneities (see Fig. 1), the hardness value measured with $500 \mathrm{~g}$ reflects the average behavior of the material. The flow stress determined as one third of the hardness was $1758 \pm 100 \mathrm{MPa}$ which is only slightly higher than the average saturation flow stress determined by pillar compression. This result suggests that the flow stress values obtained from the micropillar compression reflect the macroscopic behavior, so that the "size effect" is negligible. This observation is in line with a former study which revealed the lack of "size effect" for nanocrystalline $\mathrm{Cu}$ with the grain size of $\sim 30 \mathrm{~nm}$ even if the pillar size was only $\sim 0.4 \mu \mathrm{m}[8]$.

\section{Conclusions}

1. $\mathrm{Co} / \mathrm{Cr} / \mathrm{Fe}-$ rich and $\mathrm{Mn} / \mathrm{Ni}$-rich regions were found in a nanocrystalline $\mathrm{Co}_{20} \mathrm{Cr}_{20} \mathrm{Fe}_{20} \mathrm{Mn}_{20} \mathrm{Ni}_{20}$ HEA. The local mechanical behavior was studied by micropillar compression. The heights and the widths of the pillars were 2 and $1 \mu \mathrm{m}$, respectively, in accordance with the length scale of the chemical inhomogeneities and the grain size of the HEA.

2. Only slight differences were found between the stress-strain curves recorded in $\mathrm{Co} / \mathrm{Cr} / \mathrm{Fe}-$ rich and $\mathrm{Mn} / \mathrm{Ni}$-rich volumes, suggesting that the chemical heterogeneities in the $\mathrm{Co}_{20} \mathrm{Cr}_{20} \mathrm{Fe}_{20} \mathrm{Mn}_{20} \mathrm{Ni}_{20}$ HEA have only a negligible effect on the local mechanical behavior.

3. The average saturation flow stress obtained by pillar compression was $1535 \pm 68 \mathrm{MPa}$ which is only slightly smaller than the value determined as one third of the 
macrohardness $(1758 \pm 100)$. This observation suggests a negligible size effect in the present micropillar compression experiments.

\section{Acknowledgements}

The authors are indebted to the Hungarian Scientific Research Fund, OTKA, Grant no. K 109021 for financial support. A.H. was supported through the New National Excellence Program of the Ministry of Human Capacities, and T.G.L. was supported by the European Research Council under ERC Grant Agreement No. 267464-SPDMETALS.

\section{References}

[1] J.W. Yeh, S.K. Chen, S.J. Lin, J.Y. Gan, T.S. Chin, T.T. Shun, C.H. Tsau, S.Y. Chang, Nanostructured high-entropy alloys with multiple principal elements: novel alloy design concepts and outcomes, Adv. Eng. Mater. 6 (2004) 299-303.

[2] B. Cantor, I.T.H. Chang, P. Knight, A.J.B. Vincent, Microstructural development is equiatomic multicomponent alloys, Mater. Sci. Eng. A 375-377 (2004) 213-218.

[3] D.B. Miracle, J.D. Miller, O.N. Senkov, C. Woodward, M.D. Uchic, J. Tiles, Exploration and development of high entropy alloys for structural applications, Entropy 16 (2014) 494-525.

[4] A. Heczel, M. Kawasaki, J.L. Lábár, J. Jang J, T.G. Langdon, J. Gubicza, Defect structure and hardness in nanocrystalline CoCrFeMnNi High-Entropy Alloy processed by HighPressure Torsion, Journal of Alloys and Compounds 711 (2017) 143-154

[5] D.M. Dimiduk, C. Woodward, R. LeSar, M.D. Uchic, Scale-free intermittent flow in crystal plasticity, Science 312 (2006) 1188-1190.

[6] Z.Y. Liu, S. Guo, X.J. Liu, J.C. Ye, Y. Yang, X.L. Wang, L. Yang, K. An, C.T. Liu, Micromechanical characterization of casting-induced inhomogeneity in an A10.8CoCrCuFeNi high-entropy alloy, Scripta Materialia 64 (2011) 868-871.

[7] A.H.W. Ngan, X.X. Chen, P.S.S. Leung, R. Gu, K.F. Gan, Size effects of micrometerscaled metals - the search continues for materials containing real microstructures, MRS Communications 7 (2017) 131-140.

[8] N.L. Okamoto, D. Kashioka, T. Hirato, H. Inui, Specimen- and grain-size dependence of compression deformation behavior in nanocrystalline copper, International Journal of Plasticity 56 (2014) 173-183 


\section{Figure captions}

Fig. 1: Elemental maps for the CoCrFeMnNi HEA obtained by EDS. The brighter the color, the higher the concentration. The dashed and solid white circles indicate $\mathrm{Co} / \mathrm{Cr} / \mathrm{Fe}-\mathrm{rich}$ and $\mathrm{Mn} / \mathrm{Ni}$-rich regions where micropillar compression tests were carried out.

Fig. 2: Micropillar fabricated in a $\mathrm{Co} / \mathrm{Cr} / \mathrm{Fe}$ rich region (a) before and (b) after compression.

Fig. 3: Typical engineering stress-strain curves obtained by pillar compression for the $\mathrm{Co} / \mathrm{Cr} / \mathrm{Fe}$-rich and the $\mathrm{Mn} / \mathrm{Ni}$-rich regions. The bars indicate the errors of the flow stress values determined from compressions of different pillars. 

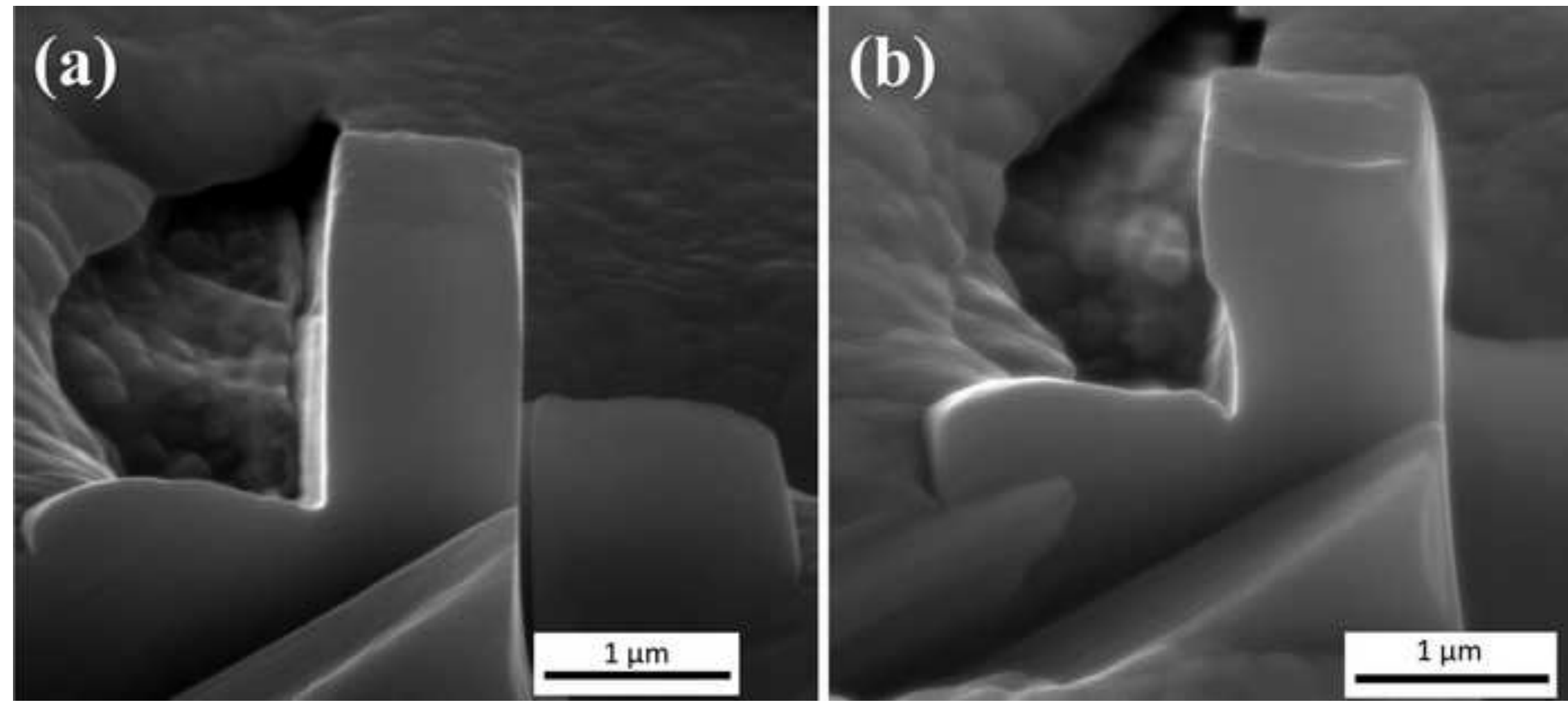


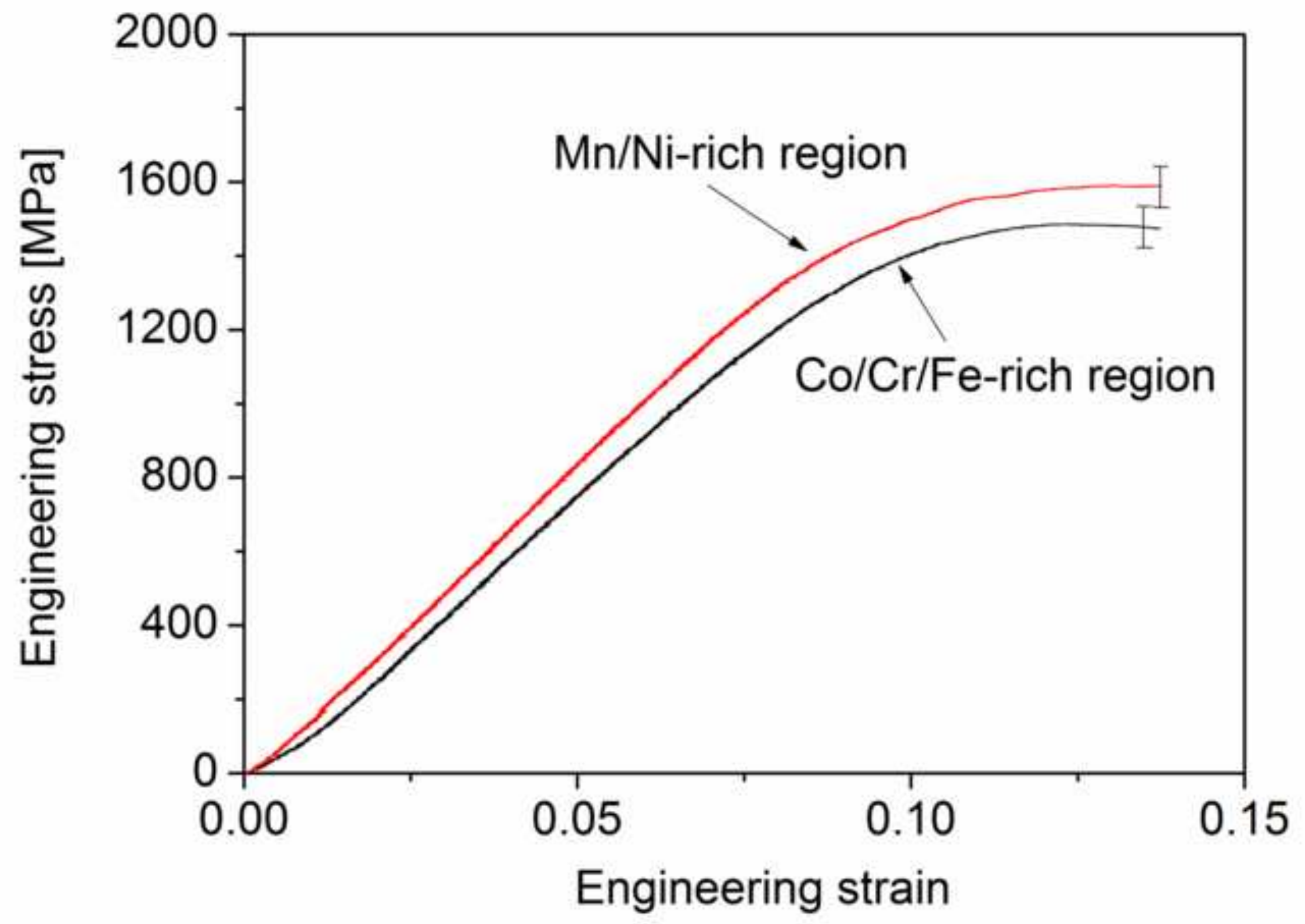

